\title{
Incidence of Recurrent Differentiated Thyroid Carcinoma in Paediatrics and Adolescents after Thyroid Surgery: A Meta-Analysis Study of Last 20 Years
}

\author{
MUHAMMAD B. ABDALFATAH, M.Sc.; AYMAN A. ALBAGHDADY, M.D.; AHMED M. KAMAL, M.D. and \\ EHAB M.A. FADL, M.D.
}

The Department of Pediatric Surgery, Faculty of Medicine, Ain Shams University

\begin{abstract}
Background: Childhood onset differentiated thyroid cancer is distinct from the adult-onset disease being more aggressive at the time of initial evaluation with a higher risk category for disease recurrence; however, it is ultimately less lethal. Unfortunately, there is no consensus regarding the means of follow-up, timing and management strategy regarding pediatric differentiated thyroid cancer. For these reasons, unique management for children and adolescents with thyroid tumors are needed.
\end{abstract}

Aim of Study: To locate relevant studies comparing incidence of recurrent differentiated thyroid carcinoma in paediatrics and adolescents after thyroid surgery modalities most commonly used in childhood onset differentiated thyroid cancer that are published in the period from June 1999 to June 2019, revising all these studies, and designing metaanalysis study to assess the overall results and define which management may provide better outcome and fewer rate of complications.

Patients and Methods: The search strategy above will be viewed,and articles that appear to fulfil the inclusion criteria will be retrieved in full. Each article identified will be reviewed and categorized into one of the following groups: Included or excluded. When there will be a doubt, a second reviewer will assess the article and a consensus will be reached.

Results: Medline databases (PubMed, Medscape, Science Direct. EMF-Portal) and all materials available in the Internet till 2019.

Conclusion: All children will require life-long surveillance after thyroid surgery, especially for thyroid cancer. Paediatric thyroid cancer is rare. (The incidence of differentiated thyroid cancer is 1 per $1,000,000$ in children less than 10 years of age). It is a treatable disease with an excellent prognosis. Treatment with radioactive iodine is recommended for most children after total thyroidectomy for papillary and follicular cancer. Radioiodine ablation should be carried about 4 weeks after surgery, with a diagnostic scan 6 months later. Regular review should include neck palpation, serum thyroglobulin, and ultrasound with cytology if necessary. In case of a cancer,

Correspondence to: Dr. Muhammad B. Abdalfatah, E-Mail: drmbadr91@gmail.com follow-up ultrasound and TSH-suppressed thyroglobulin (Tg) level assessment is performed 6 months after initial therapy and at least annually thereafter, although it may be preferable to observe patients every 6 months for at least 5 years after diagnosis of more advanced initial or metastatic cancer. Assessment of free T4, T3, and TSH levels is indicated every 6 months, and 1-2 months after dosage changes. Calcitonin is a marker of recurrent disease in medullary cancer. This suggests that an aggressive operative approach to lymph node resection may be safer (lower recurrence, lower complications) in experienced hands than a less complete resection in a lower volume center.

Key Words: Thyroid malignancy - Paediatrics - Thyroidectomy.

\section{Introduction}

CHILDHOOD onset DTC is distinct from the adult-onsetdisease, being more aggressive at the time ofinitial evaluation with a higher risk category fordisease progression and recurrence. Differentiated thyroid cancer inpatients $<21$ years of age is associated with local invasion in $18-67 \%$, cervical lymph node involvement in $37-90 \%$, and distant metastases involvementin 7-28\% [1]

The predominant thyroid malignant histologies afflicting adults, namely papillary, follicular, and medullary cancer, are seen with similar frequency in children and adolescents. However, at the time of diagnosis, children present more often with advanced disease than adults [2]

Thyroid nodules in pediatric patients have a higher risk of malignancy and lymph node metastasis than in adults but are managed with similar methods, consisting primarily of total thyroidectomy and neck dissection [3].

Among 15-to 19-year old adolescents, thyroid cancer is the eighth most frequently diagnosed cancer and the second most common cancer among 
girls. Adolescents have a 10 -fold greater incidence than younger children, and there is a female to male preponderance $(5: 1)$ during adolescence that is not seen in young children. The most common presentation for differentiated thyroid cancer in children is that of a thyroid nodule [4].

Although pediatric patients with thyroid carcinoma tend to present with disease at a more advanced stage than adults, namely, a higher incidence of lymph node and pulmonary metastasis, the prognosis for death from disease is much better for the pediatric patients. In particular, recommendations have been made to not perform a total thyroidectomy and lymph node dissection. Conversely, some investigators believe that the use of total thyroidectomy, lymph node dissection, and post-operative ${ }^{131}$ therapy is best to treat this condition [5].

It is stated that children often present with more advanced locoregional disease and distant metastases than their adult counterparts. The clinical presentation has, however, changed over the last several decades. In the past, nearly $50 \%$ of children had a history of ionizing radiation exposure to the head or neck. Today that figure, outside of the Chernobyl disaster region, has dropped to less than $3 \%[6]$.

The accident at the Chernobyl nuclear power station in April 1986 resulted in a dramatic increase in thyroid cancer incidence, especially in young residents of the contaminated territories in Belarus, Ukraine, and Russia, which led to a uniquely rapid accumulation of experience in the treatment of this otherwise rare human malignancy. According to published observations, post-Chernobyl pediatric thyroid cancer is almost exclusively presented by papillary carcinomas with frequent lymph node involvement at diagnosis and a high incidence of recurrence after treatment [7].

The pre-operative evaluation of the newly diagnosed pediatric papillary thyroid carcinoma patient is critical for optimizing surgical outcome and medical therapy. In all cases, a comprehensive neck US using a high-resolution probe $(7.5 \mathrm{MHz}$ or higher) and Doppler technique should be obtained by an experienced ultrasonographer. All regions of the neck should be interrogated, recognizing that US has decreased sensitivity to identify malignant lymphadenopathy in the central neck (level VI) $(152,153)$ [4].

There is good evidence that FNA in the pediatric population is a sensitive diagnostic test and is a useful tool for excluding malignancy [8]
The stepwise combination of surgery and radioiodinetherapy is curative with an overall survival rate rangingfrom $86 \%$ to $100 \%$ [7].

Surgical decision-making is a balance between completeness of removal and quality of patient's life, so a variety of clinical parameters should be taken into account and special attention should be paid to tumor staging, careful separation of parathyroid glands, and recurrent laryngeal nerves at the time of surgery [7].

Prophylactic thyroidectomy reduces recurrence and post-operative complications in pediatric patients with MEN2. Early thyroidectomy based on only calcitonin level could possibly reduce thyroidectomy delay [9].

The incentive to delay prophylactic thyroidectomy is to optimize patient safety by operating on older children, whose surgery is technically less difficult and in whom treatment of iatrogenic hypoparathyroidism may be easier. Children undergoing thyroidectomy or parathyroidectomy have higher complication rates than adults, and have better outcomes when operated on by high-volume surgeons [10]

Aim of the work:

The aim is to locate relevant studies comparing incidence of recurrent differentiated thyroid carcinoma in paediatrics and adolescents after thyroid surgery modalities most commonly used in Childhood onset differentiated thyroid cancer that are published in the period from June 1999 to June 2019 , revising all these studies, and designing meta-analysis study to assess the overall results and define which management may provide better outcome and fewer rate of complications.

\section{Patients and Methods}

\section{Criteria for considering studies for this review:}

Types of studies: Published studies about incidence of recurrent differentiated thyroid carcinoma in paediatrics and adolescents after thyroid surgery with thyroid malignancies that are carried out in the period from June 1999 to June 2019. Types of participants: Paediatric patients up to 22 years old with differentiated thyroid cancer. Types of interventions: Most frequently used management modalities in differentiated thyroid cancer with their outcome assessment. Types of outcome measures: Surgical outcomes and reported complications including recurrence.

Search strategy for identification of studies: A systematic review will be performed in accordance 
with the PRISMA and PICO guidelines. An initial search will be carried out using two online databases: PubMed/MEDLINE and Science direct. The following search terms will be employed: "(Thyroid malignancy AND paediatrics) AND (thyroidectomy OR outcome OR management OR results OR complications OR recurrence)".

\section{Methods of the review:}

Locating and selecting studies: Abstracts of articles identified using the search strategy above will be viewed, and articles that appear to fulfil the inclusion criteria will be retrieved in full. Each article identified will be reviewed and categorized into one of the following groups: Included or excluded. When there will be a doubt, a second reviewer will assess the article and a consensus will be reached.

For a study to be included, it needs to: Include paediatric participants who had been operated on for differentiated thyroid cancer in childhood period for the first time. Provide sufficient detail on the above outcome measures to allow comparison across studies. Report quantitative data. Be written in English language. Be published in full-text and in a peer-reviewed journal.

Data extraction: A copy of each paper identified will be obtained, and relevant data will be abstracted for a quantitative overview. In case of discrepancies or when the information presented in a study is unclear, abstraction by a second reviewer will be sought to resolve the discrepancy. All included articles will be assessed for quality regarding methodological strength as per the 2009 Cochrane collaboration updated guidelines for systematic reviews. The quality of articles will be assessed by two reviewers and in case of any disagreement, consensus will be achieved by discussion. The main outcome measures will be incidence of recurrent differentiated thyroid carcinoma in paediatrics and adolescents after thyroid surgery.

\section{Statistical analysis:}

All analyses were performed using Stata/SE 12.0 statistical software (StataCorp, College Station, TX, USA). 95\% Confidence Intervals (CI) was also calculated to establish the usefulness of recurrence after surgery. The Higgins test was performed to check the heterogeneity of the studies analysed. On the basis of this test, summary estimates of predictive values in terms of injury were made using the Mantel-Haenszel method, which is based on the fixed-effects model. Publication bias was as-sessed using a funnel plot and Egger's method.
The relative contribution of each study to the metaanalysis was calculated according to the amount of information it contained, the number of surgery at risk and their variability. The influence of individual studies on the summary-effect estimate was evaluated using influence analysis. Meta-regression analysis was conducted to investigate whether the type of study (randomised or other) was associated with the treatment effect. Statistical significance was set at $p<0.05$. Unless otherwise specified, the $p$-value was considered to be 2 -tailed.

Evidence of publication bias: Will be sought using the funnel plot method. A funnel plot is a simple scatter plot of the intervention effect estimates from individual studies against some measure of each study's size or precision.

A star rating of 0-9 was allocated to each study based on three parameters; [S, selection (0-4); C, Comparability (0-2); O, Outcome (0-3)]. Studies receiving six or more stars were considered of good quality (Raj et al., 2015; Zhang, 2015). Details of this assessment scale are demonstrated in (Table 1).

Table (1): Risk of bias between studies

\begin{tabular}{cllll}
\hline Domain & Selection & Comparability & Outcome & Quality \\
\hline Assessment 3 or 4 stars & 1 or stars & 2 or 3 stars & Good \\
2 stars & 1 or 2 stars & 2 or 3 stars & Fair \\
0 or 1 star & 1 or 2 stars & 2 or 3 stars & Poor \\
\hline
\end{tabular}

\section{Results}

We identified provided 278 studies as potentially. After duplicates removal and abstract screening, 39 studies were excluded after screening the titles and abstracts. Finally, 10 studies were fully evaluated retrieved for fully evaluated. One additional studies were subsequently excluded due to inappropriate intervention, 1 study had insufficient data, and 2 studies were conducted with inappropriate control groups being operated for hypospadias for the first time.

The nine studies selected included a total of 2017 patients with 257 at risk. Table (2) details the characteristics of the studies included in the meta-analysis. The mean age of patients was 1021 years and the sex ratio was 1:5.9 (range 1-20).

We searched for articles published before May 2019 in Medline, CINAHL, the Cochrane Library, Scopus, ProQuest. 


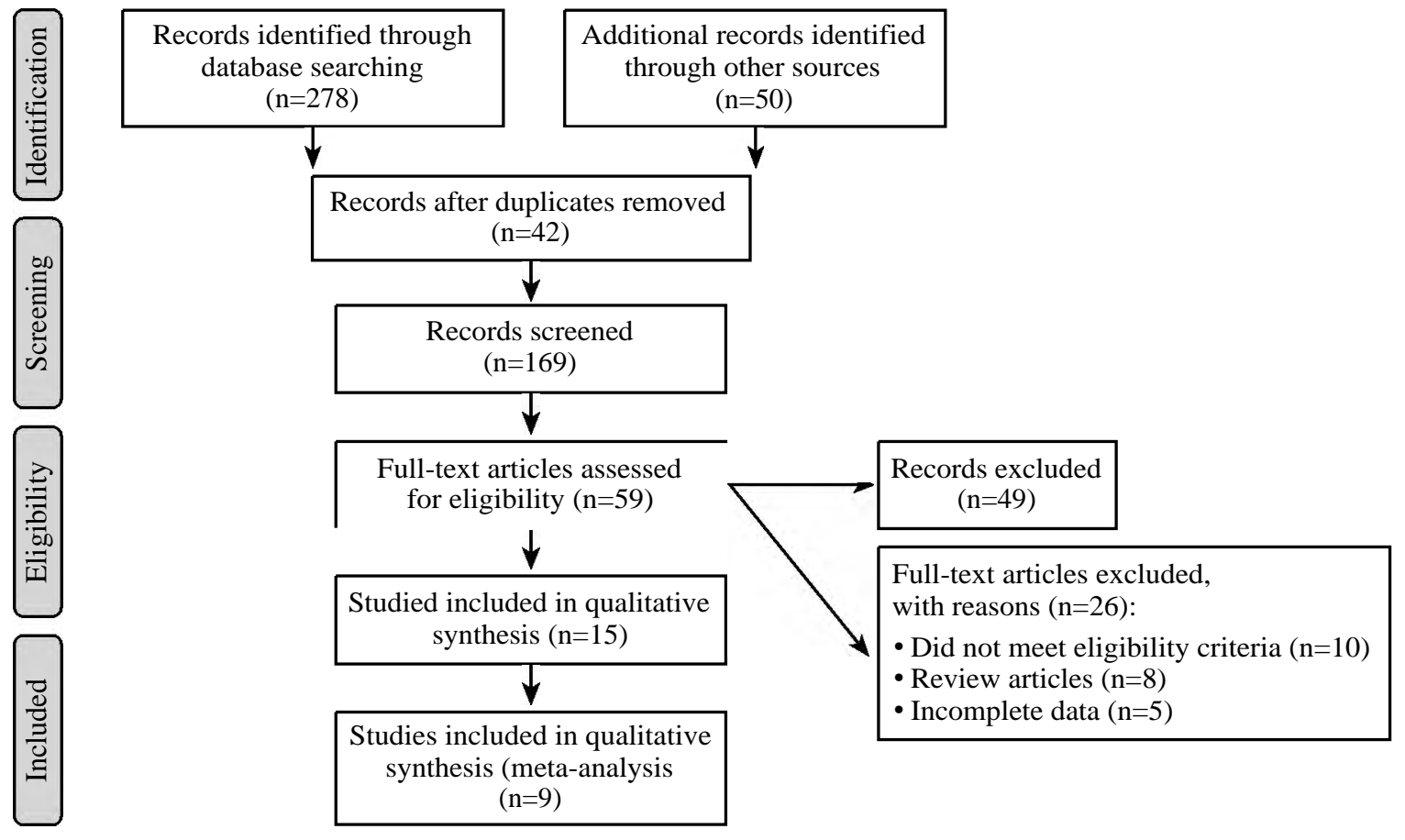

Fig. (1): Flow chart of the study after excluding ineligible studies, eight articles were identified for full review

[11-19].

Table (2): Demographic characteristics patients in the included studies.

\begin{tabular}{lccccc}
\hline \multirow{2}{*}{ Study } & $\begin{array}{c}\text { No. of } \\
\text { patients }\end{array}$ & $\begin{array}{c}\text { Gender } \\
\text { M/F }\end{array}$ & Range & \multicolumn{2}{c}{ Age at surgery, years } \\
\cline { 5 - 6 } & & $1: 2.8$ & $4.5-16.8$ & 12.6 (NA) & 12.8 \\
\hline Alessandri et al. [11] & 54 & $1: 3.3$ & $4-20$ & 15.8 (NA) & 11.0 \\
Grigsby et al. [5] & 56 & $1: 2.5$ & $7-20$ & NA & 18.2 \\
Giuffrida et al. [12] & 48 & $1: 1.6$ & $4.2-14.9$ & 11.7 (NA) & NA \\
Demidchik et al. [7] & 740 & $1: 3.5$ & $5-19$ & 21 (NA) & 16 \\
Bargren et al. [3] & 68 & $1: 4.3$ & $1-19$ & 15.9 (NA) & NA \\
Hogan et al. [2] & 1753 & $1: 2.4$ & $3-20$ & NA & 16 \\
Hay et al. [6] & 215 & NA & NA & NA & NA \\
Francis et al. [4] & NA & NA & & & Median \\
Byeon et al. [13] & 83 & $1: 5.9$ & $8-20$ & 16.8 (NA) & NA \\
\hline
\end{tabular}

NA: Not Applicable. M: Male. F: Female.

Table (3): Studies included in the review showing authors, years and study design.

\begin{tabular}{|c|c|c|}
\hline Study & Title & Study design \\
\hline Alessandriet al. [11] & $\begin{array}{l}\text { - Age is the major determinant of recurrence in pediatric differentiated } \\
\text { thyroid carcinoma. }\end{array}$ & Retrospective \\
\hline Grigsby et al. [5] & - Childhood and adolescent thyroid carcinoma. & Retrospective \\
\hline Giuffrida et al. [12] & - Differentiated thyroid cancer in children and adolescents. & Retrospective \\
\hline Demidchik et al. [7] & $\begin{array}{l}\text { - Comprehensive clinical assessment of } 740 \text { cases of surgically treated thyroid } \\
\text { cancer in children of Belarus. }\end{array}$ & Retrospective \\
\hline Bargren et al. [3] & - Outcomes of surgically managed pediatric thyroid cancer. & Prospective randomized \\
\hline Hogan et al. [2] & - Pediatric thyroid carcinoma: Incidence and outcomes in 1753 patients. & Prospective randomized \\
\hline Hay et al. [6] & $\begin{array}{l}\text { - Long-term outcome in } 215 \text { children and adolescents with papillary thyroid } \\
\text { cancer treated during } 1940 \text { through } 2008 \text {. }\end{array}$ & Prospective randomized \\
\hline Francis et al. [4] & $\begin{array}{l}\text { - Management guidelines for children with thyroid nodules and differentiated } \\
\text { thyroid cancer. }\end{array}$ & Prospective randomized \\
\hline Byeon et al. [13] & $\begin{array}{l}\text { - Clinical analysis of pediatric thyroid cancer: a single medical institution } \\
\text { experience of } 18 \text { years. }\end{array}$ & Retrospective \\
\hline
\end{tabular}




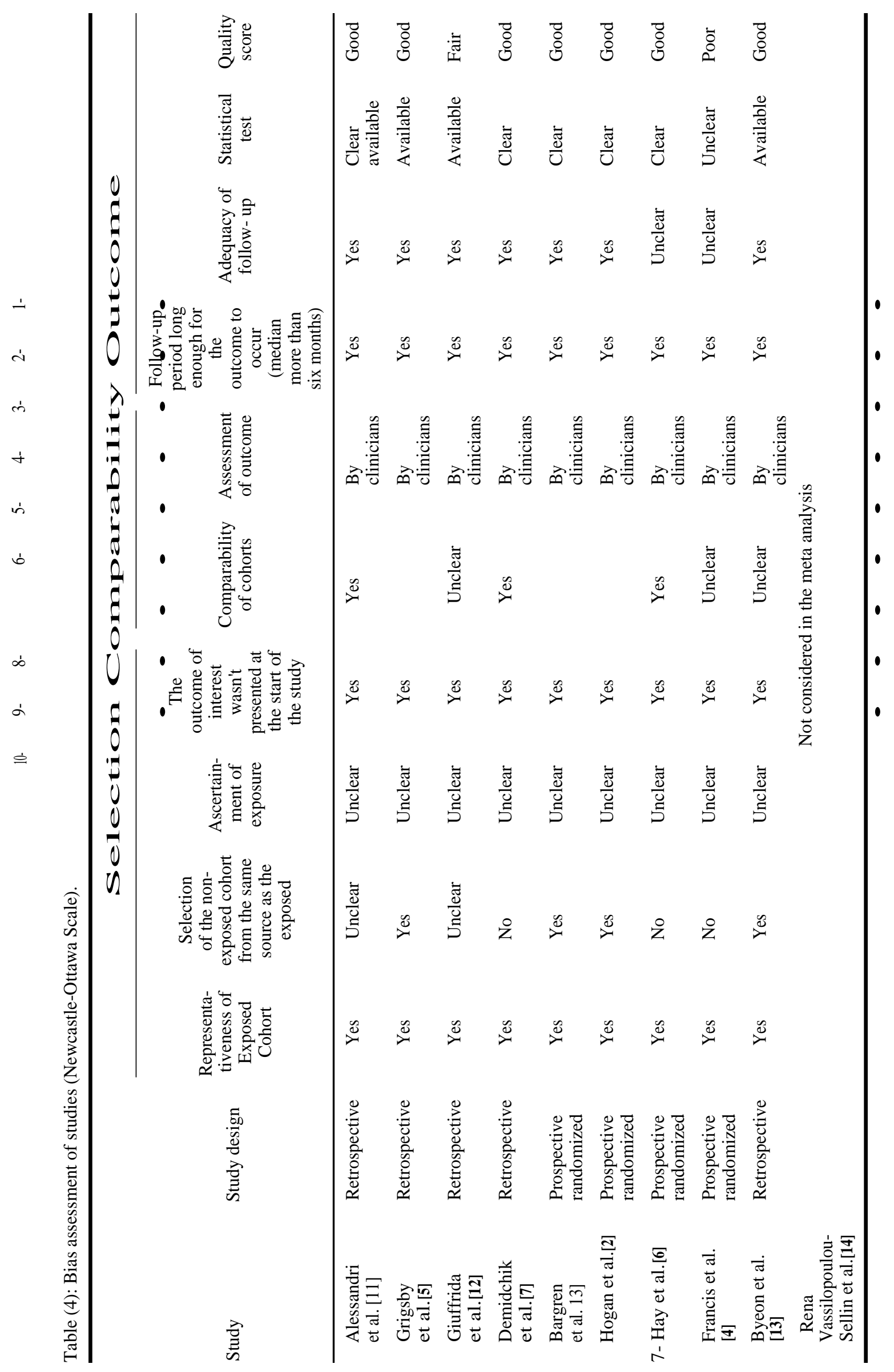


Table (5): Study.

\begin{tabular}{llcccc}
\hline Study & $\begin{array}{c}\text { Sample } \\
\text { size }\end{array}$ & $\begin{array}{c}\text { Proportion } \\
(\%)\end{array}$ & 95\% CI & \multicolumn{2}{c}{ Weight (\%) } \\
\cline { 5 - 6 } & & & & Fixed & Random \\
\hline Alessandri et al. [11] & 54 & 42.593 & 29.235 to 56.792 & 1.75 & 10.41 \\
Grigsby et al. [5] & 56 & 89.286 & 78.124 to 95.965 & 1.82 & 10.46 \\
Demidchik et al. [7] & 740 & 97.568 & 96.183 to 98.552 & 23.60 & 12.05 \\
Bargren et al. [3] & 1753 & 97.661 & 96.840 to 98.316 & 55.86 & 12.14 \\
Hogan et al. [2] & 68 & 55.882 & 43.318 to 67.918 & 2.20 & 10.73 \\
Hay et al. [6] & 215 & 93.023 & 88.754 to 96.043 & 6.88 & 11.69 \\
Giuffrida et al. [12] & 48 & 94.000 & 83.452 to 98.745 & 1.62 & 10.29 \\
Byeon et al. [13] & 83 & 92.771 & 84.927 to 97.301 & 2.68 & 10.97 \\
\hline Total (fixed effects) & 3017 & 95.890 & 95.135 to 96.557 & 100.00 & 100.00 \\
Total (random effects) & 3017 & 86.870 & 78.522 to 93.405 & 100.00 & 100.00 \\
\hline
\end{tabular}

Table (6): Test for heterogeneity.

\begin{tabular}{ll}
\hline $\mathrm{Q}$ & 214.2937 \\
$\mathrm{DF}$ & 8 \\
Significance level & $p<0.0001$ \\
$\mathrm{I}^{2}$ (inconsistency) & $96.27 \%$ \\
$95 \%$ CI for I $^{2}$ & 94.53 to 97.45 \\
\hline
\end{tabular}

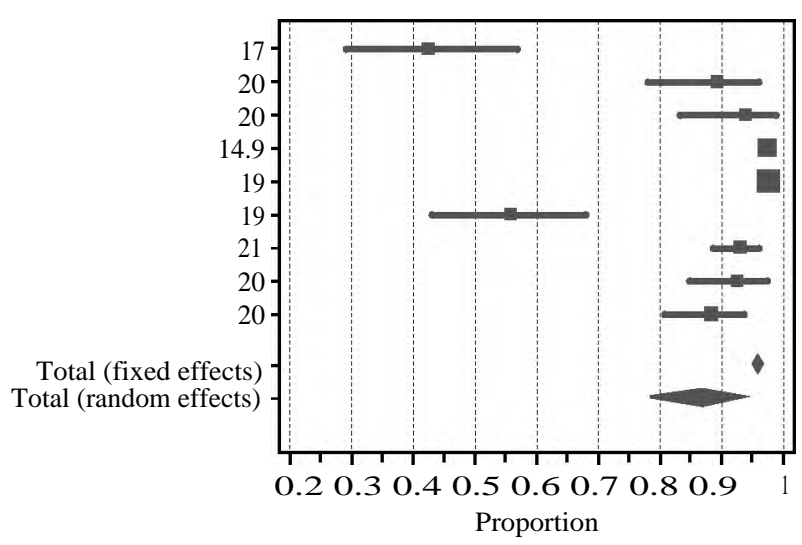

Fig. (2): Abbreviations: Cl: Confidence Interval for individual trial results and credible interval for meta-analysis results, Thyroid Screening Study. Each study is represented by a line in the plot the event rates of each study are listed.

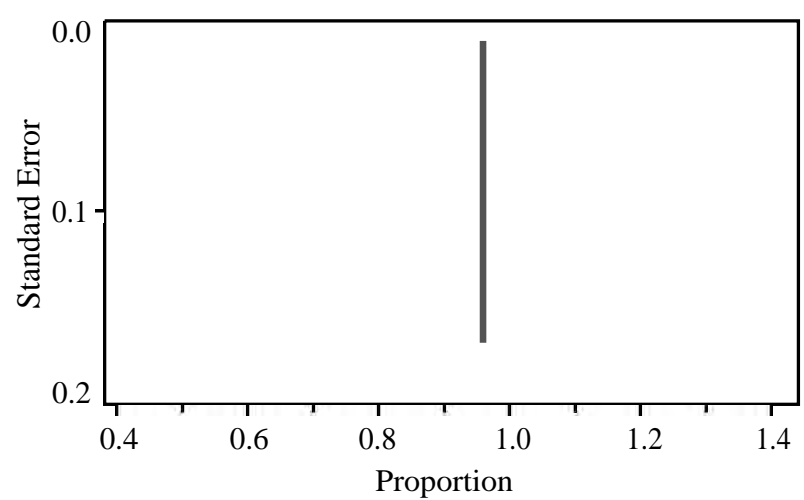

Fig. (3): Influence analysis was performed to identify studies with excessive influence Fig. (3). The Begg test revealed that no bias was found in the publications used for the meta-analysis (Kendall's score, onesided, $p=1.000)$. The type of study was not associated with the treatment effect $(p=0.078)$.

\section{Discussion}

This systematic review has demonstrated recommendations that have been based on analysis of small cohorts, multicenter retrospective reviews, and extrapolations from adult studies and guidelines concerning extent of surgical interference with recurrence rate [15]. Thyroid nodules in pediatric patients have a higher risk of malignancy and lymph node metastasis than in adults, but are managed with similar methods, consisting primarily of total thyroidectomy and neck dissection. With appropriate treatment, thyroid cancer has a very good prognosis in adults with a $90 \%$ survival rate at 20 years [16]. Interestingly, pediatric patients have a better prognosis (98.8\% 10 year survival) despite more extensive disease and equivalent treatment [7].

This review was similar to other studies with respect to age distribution; however there was a larger number of females (78\%), which usually range from $62 \%-70 \%$. The distribution of cancer types was as expected. Of patients $<19$ y old undergoing surgical resection of a malignant thyroid nodule, $53 \%$ had lymph node involvement. This finding is similar to other studies, which cite between $40 \%$ and $80 \%$ involvement. The explanation for this is that pediatric patients with a thyroid nodule are more likely to present with advanced disease with metastasis than adults with a thyroid nodule, who have a $20 \%-50 \%$ risk of lymph node involvement.

Again, this rate is higher than the adult population, in which recurrence of cancer is seen in $12 \%$ of patients [17]. A surgical procedure involving less than total thyroidectomy significantly increased the need for a repeat surgery in this review, supporting the recommendation of a total procedure for all children with malignant thyroid nodules [18]. The current practices recommend total thy- 
roidectomy as the procedure of choice irrespective of tumor size.

Hypoparathyroidism is primarily due to incidental stunning and/or removal of the parathyroid glands, which can sometimes be attached or embedded in the thyroid capsule. Another common occurrence is devascularization of the parathyroid gland during thyroid removal. Researchers continue to debate over the number of functioning parathyroids needed to maintain adequate parathyroid activity, ranging from 1 to 3 [19]. Some studies have recently recommended that at least one parathyroid be autotransplanted into a sternocleidomastoid muscle pouch, as this could reduce the rate of permanent hypoparathyroidism. Alternatively, others show that there is no link between autotransplantation and decreased permanent hypoparathyroidism.

Many studies show that total or subtotal thyroidectomy are associated with increased surgical complications and morbidity, however studies specifically investigating effects on the parathyroid gland show that total/subtotal procedures have no significant correlation to increased incidental parathyroid removal or permanent hypocalcemia $[20,21]$

In pediatric patients undergoing surgical management of well differentiated thyroid cancer, a total thyroidectomy is recommended. Our study confirmed that a primary procedure involving less than total thyroidectomy significantly increased the need for repeat surgery. In addition, we found no significant increase in morbidity or surgical complications with total thyroidectomy. Nevertheless, this review provided valuable and up-to-date information in this field. It also presented some data which is different from previous reports. The level of evidence on which our review was based was moderate and the quality of included studies were generally good. Our results are in favor of a total thyroidectomy as the preferred method of surgical management in both adults and children for thyroid malignancy. A total thyroidectomy is desired in children, especially due to more extensive disease upon diagnosis and a higher rate of spread. In addition, a total thyroidectomy has been demonstrated in other studies to reduce risk of cancer recurrence, for which children are at greater risk.

\section{Conclusion:}

All children will require life-long surveillance after thyroid surgery, especially for thyroid cancer. Paediatric thyroid cancer is rare. (The incidence of differentiated thyroid cancer is 1 per $1,000,000$ in children less than 10 years of age). It is a treatable disease with an excellent prognosis. Treatment with radioactive iodine is recommended for most children after total thyroidectomy for papillary and follicular cancer. Radioiodine ablation should be carried about 4 weeks after surgery, with a diagnostic scan 6 months later. Regular review should include neck palpation, serum thyroglobulin, and ultrasound with cytology if necessary. In case of a cancer, follow-up ultrasound and TSH-suppressed thyroglobulin $(\mathrm{Tg})$ level assessment is performed 6 months after initial therapy and at least annually thereafter, although it may be preferable to observe patients every 6 months for at least 5 years after diagnosis of more advanced initial or metastatic cancer. Assessment of free T4, T3, and TSH levels is indicated every 6 months, and 1-2 months after dosage changes. Calcitonin is a marker of recurrent disease in medullary cancer. This suggests that an aggressive operative approach to lymph node resection may be safer (lower recurrence, lower complications) in experienced hands than a less complete resection in a lower volume center.

\section{References}

1- RACHMIEL M., CHARRON M., GUPTA A., et al.: 'Evidence-based review of treatment and follow-up of pediatric patients with differentiated thyroid carcinoma', Journal of Pediatric Endocrinology and Metabolism, 19 (12): 1377-93, 2006.

2- HOGAN A.R., YING Z., EDUARDO A.P., et al.: 'Pediatric Thyroid Carcinoma: Incidence and Outcomes in 1753 Patients', Journal of Surgical Research. Elsevier Ltd, 156 (1): 167-72, 2009.

3- BARGREN A.E., GOSWIN Y., MEYER-ROCHOW C., et al.: 'Outcomes of Surgically Managed Pediatric Thyroid Cancer', Journal of Surgical Research. Elsevier Ltd, 156 (1): 70-3, 2009

4- FRANCIS G.L., STEVEN G.W., ANDREW J.B., et al.: 'Management Guidelines for Children with Thyroid Nodules and Differentiated Thyroid Cancer', Thyroid, 25 (7): 716-59, 2015.

5- GRIGSBY P.W., ANAT G., JEFF M.M., et al.: 'Childhood and adolescent thyroid carcinoma', Cancer, 95 (4): 7249, 2002.

6- HAY I.D., TOMAS G.L., MEGAN S.R., et al.: 'Longterm outcome in 215 children and adolescents with papillary thyroid cancer treated during 1940 through 2008', World Journal of Surgery, 34 (6): 1192-202, 2010.

7- DEMIDCHIK Y.E., EUGENE P.D., CHRISTOPH R., et al.: 'Comprehensive clinical assessment of 740 cases of surgically treated thyroid cancer in children of Belarus', Annals of Surgery, 243 (4): 525-32, 2006.

8- STEVENS C., JUSTIN K.P.L., MOHSEN S., et al.: 'Pediatric thyroid fine-needle aspiration cytology: A metaanalysis', Journal of Pediatric Surgery. Elsevier Inc., 44 (11): pp. 2184-91. doi: 10. 10 16/j.jpedsurg.2009.07.022, 2009. 
9- MATSUSHITA R., KEISUKE NAGASAKI, TADAYUKI AYABE, et al.: 'Present status of prophylactic thyroidectomy in pediatric multiple endocrine neoplasia 2: A nationwide survey in Japan 1997-2017', Journal of Pediatric Endocrinology and Metabolism, 32 (6): pp. 585-95. doi: 10.1515/jpem-2018-0444, 2019.

10- KLOOS R.T., CHARIS E., DOUGLAS B.E., et al.: 'Medullary thyroid cancer: Management guidelines of the American Thyroid Association.', Thyroid: Official Journal of the American Thyroid Association, 19 (6): 565-612, 2009.

11- ALESSANDRI A.J., GODDARD K.J., BLAIR G.K., FRYER C.J. and SCHULTZ K.R.: Age is the major determinant of recurrence in pediatric differentiated thyroid carcinoma. Medical and Pediatric Oncology: The Official Journal of SIOP-International Society of Pediatric Oncology (Societé Internationaled' Oncologie Pédiatrique, 35 (1): 41-6, 2000.

12- GIUFFRIDA D., SCOLLO C., PELLEGRITI G., LAVENIA G., IURATO M.P., PEZZINO V. and BELFIORE A.: Differentiated thyroid cancer in children and adolescents. Journal of endocrinological investigation, 25 (1): 18-24, 2002.

13- BYEON H.K., KIM S.B., OH H.S., KIM H.K., CHOI I.H., KIM H., CHO J.G., OH K.H., BAEK S.K., WOO J.S. and KWON S.Y.: Clinical analysis of pediatric thyroid cancer: A single medical institution experience of 18 years. Annals of Otology, Rhinology \& Laryngology, 128 (12): 1152-7, 2019.

14-VASSILOPOULOU-SELLIN R., GOEPFERT H., RANEY B. and SCHULTZ P.N.: Differentiated thyroid cancer in children and adolescents: Clinical outcome and mortality after long-term follow-up. Head \& Neck: Journal for the Sciences and Specialties of the Head and Neck, 20 (6): 549-55, 1998

15- BRINK J., VAN HEERDEN J., McIVER B., et al.: Papillary thyroid cancer with pulmonary metastases in children: Long-term prognosis. Surgery, 128: 881-6, 2000.

16-PARISI M.T. and MANKOFF D.: Differentiated pediatric thyroid cancer: Correlates with adult disease, controversies in treatment. Semin. Nucl. Med., 37: 340, 2007.

17- CHEEMA Y., REPPLINGER D., ELSON D., et al.: Is tumor size the best predictor of outcome for papillary thyroid cancer? Ann. Surg. Oncol., 13: 1524, 2006.

18-HANDKIEWICZ-JUNAK D., WLOCH J., CZARNIECKA A., et al.: Completion total thyroidectomy in children with differentiated thyroid cancer. Endokrynol. Pol., 57: 356, 2006.

19- ROSATO L., AVENIA N., BERNANTE P., et al.: Complications of thyroid surgery: Analysis of a multicentric study on 14,934 patients operated on in Italy over 5 years. World J. Surg., 28: 271, 2004.

20- SAKORAFAS G.H., STAFYLA V., BRAMIS C., et al.: Incidental parathyroidectomy during thyroid surgery: An underappreciated complication of thyroidectomy. World J. Surg., 29: 1539, 2005.

21- GOURGIOTIS S., MOUSTAFELLOS P., DIMOPOULOS N., et al.: Inadvertent parathyroidectomy during thyroid surgery: The incidence of a complication of thyroidectomy. Langenbecks Arch. Surg., 391: 557, 2006. 


\section{طرق العلاج المختلفة للآورام المختلفة الخبيثة بالغدة الدرقية في الآطفال}

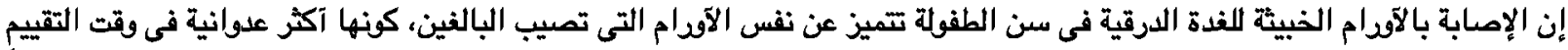

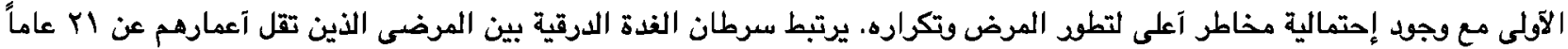

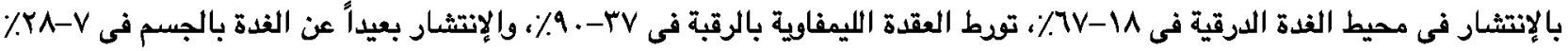

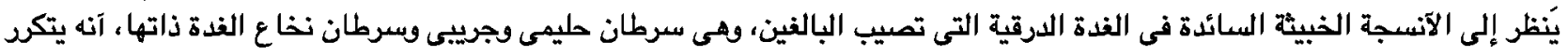
بصورة مماثلة عند الآطفال والمراهقين ومع ذلك، فى وقت التشخيص، يصاب الآطفال في كثير من الآحيان بمرض متقدم آكثر من البالغين. تكون العقيدات الدرقية لدى مرضى الآطفال آكثر عرضة لإصصابة بمرض الودم الخبيث والإنتثار إلى العقد الليمفاوية آكثر من البالغين،

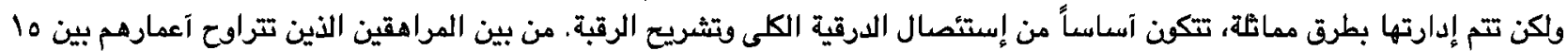

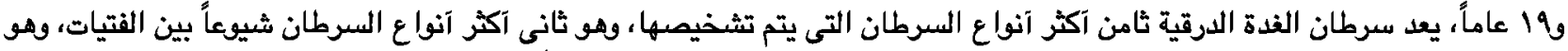

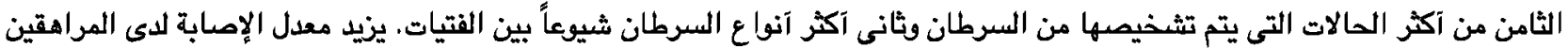

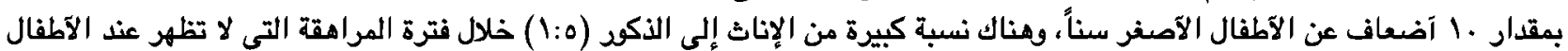
الصغار. العرض الآكثر شيوعاً لسرطان الغدة الدرقية متباينة فى الآطفال هو آن الآناف العقيدات الدرقية.

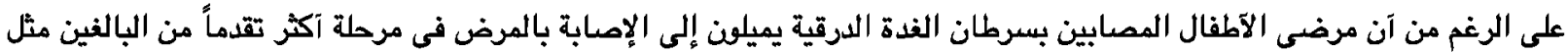

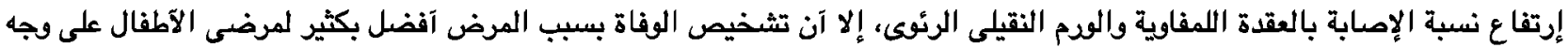

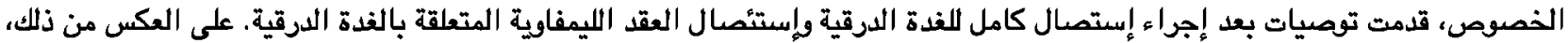

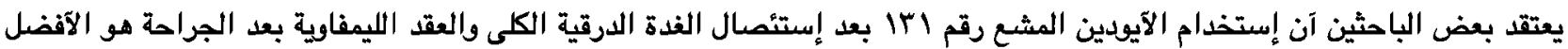

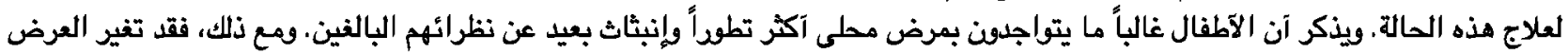

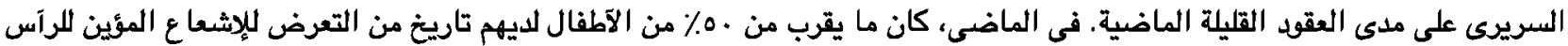

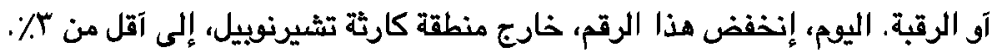

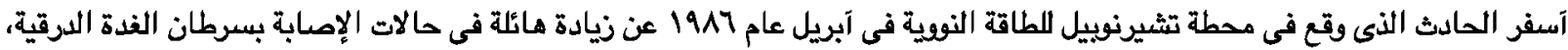

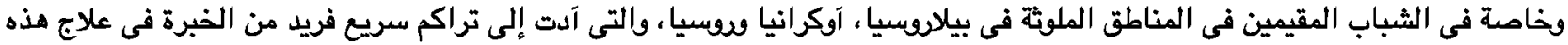

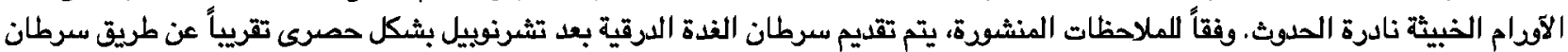

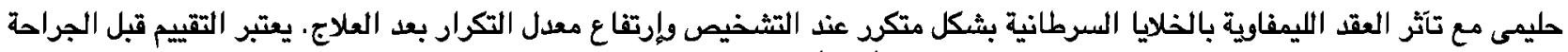

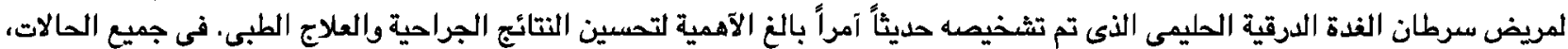

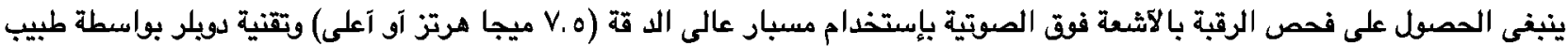
آشعقة نو خبرة.

هنائ آدلة جيدة على آن في مجتمع الآطفال يعل سحب عينة بإبرة شفط من نسيج الغدة الدرقية هو إختبار تثخيصى حساس وآداة مفيدة الإستبعاد الآورام الخبيثة.

يعد الجمع بين الجراحة والعلاج باليود المشع علاج مع معدل البقاء على قيد الحياة عموماً يتراوح بين 11٪ إلى ..1٪.

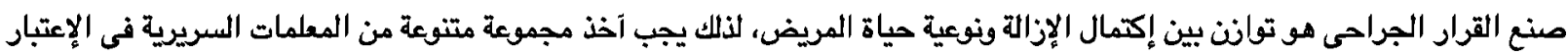

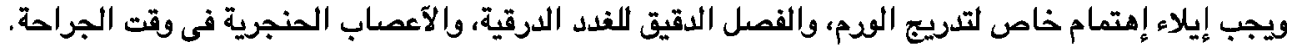

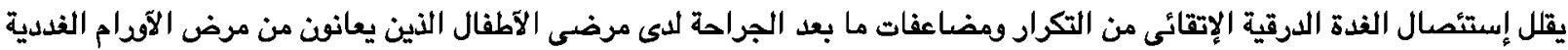

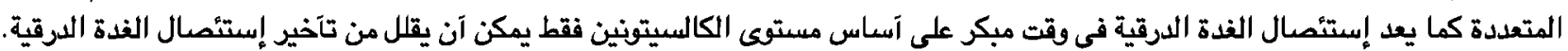

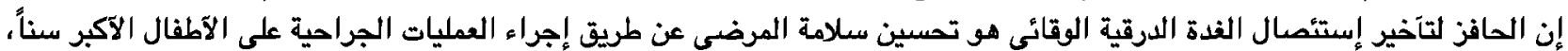
الذين تكن عمليتهم آقل صعوية من الناحية الفنية والذين قد يكون علاج قصدو الفين الغدة الدرقية لديهم آسهرل. 